\title{
Investigation of Low-Pressure Bimetallic Cobalt-Iron Catalyst-Grown Multiwalled Carbon Nanotubes and Their Electrical Properties
}

\author{
Muhammad Aniq Shazni Mohammad Haniff, ${ }^{1,2}$ Hing Wah Lee, ${ }^{1}$ Wai Yee Lee, ${ }^{1}$ \\ Daniel C. S. Bien, ${ }^{1}$ Khairul Anuar Wahid, ${ }^{1}$ Mai Woon Lee, ${ }^{1}$ and Ishak Abd. Azid ${ }^{2}$ \\ ${ }^{1}$ NEMS and Photonics Cluster, MIMOS Berhad, Technology Park Malaysia, 57000 Kuala Lumpur, Malaysia \\ ${ }^{2}$ School of Mechanical Engineering, USM Engineering Campus, Universiti Sains Malaysia, 14300 Nibong Tebal, Pulau Pinang, Malaysia \\ Correspondence should be addressed to Muhammad Aniq Shazni Mohammad Haniff; aniq.haniff@mimos.my
}

Received 4 August 2013; Accepted 14 October 2013

Academic Editor: John Zhanhu Guo

Copyright (C) 2013 Muhammad Aniq Shazni Mohammad Haniff et al. This is an open access article distributed under the Creative Commons Attribution License, which permits unrestricted use, distribution, and reproduction in any medium, provided the original work is properly cited.

\begin{abstract}
A bimetallic cobalt-iron catalyst was utilized to demonstrate the growth of multiwalled carbon nanotubes (CNTs) at low gas pressure through thermal chemical vapor deposition. The characteristics of multiwalled CNTs were investigated based on the effects of catalyst thickness and gas pressure variation. The results revealed that the average diameter of nanotubes increased with increasing catalyst thickness, which can be correlated to the increase in particle size. The growth rate of the nanotubes also increased significantly by $\sim 2.5$ times with further increment of gas pressure from 0.5 Torr to 1.0 Torr. Rapid growth rate of nanotubes was observed at a catalyst thickness of $6 \mathrm{~nm}$, but it decreased with the increase in catalyst thickness. The higher composition of $50 \%$ cobalt in the cobalt-iron catalyst showed improvement in the growth rate of nanotubes and the quality of nanotube structures compared with that of $20 \%$ cobalt. For the electrical properties, the measured sheet resistance decreased with the increase in the height of nanotubes because of higher growth rate. This behavior is likely due to the larger contact area of nanotubes, which improved electron hopping from one localized tube to another.
\end{abstract}

\section{Introduction}

Carbon nanotubes (CNTs) have elicited much interest due to their excellent electrical and mechanical properties that make them desirable for numerous potential applications such as field emission [1], atomic force microscopy tips [2], gas and vapor sensors [3], supercapacitors [4], and transistors [5]. To achieve maximum potential in target application, nanotubes with well-defined diameter, length, position, and optimized growth direction are necessary. When developing vertically aligned CNTs grown by chemical vapor deposition (CVD), the growth of the CNTs depends on the catalyst film thickness, substrate type, ratio of feed gas, temperature, and gas pressure. Several studies have been carried out to grow multiwalled carbon nanotubes (MWCNTs) from CVD or plasma-enhanced CVD using single-metal $\mathrm{Co}, \mathrm{Fe}$, and $\mathrm{Ni}$ as catalysts on various substrates [6-8]. To further improve the density of MWCNTs, plasma pretreatment is performed on these typical catalyst particles to enhance catalyst formation and stability onto the substrate [9]. Various studies on the effectiveness of using multilayered catalysts or alloys, such as $\mathrm{Fe}-\mathrm{Ni}[10,11], \mathrm{Fe}-\mathrm{Mo}$ [12], and $\mathrm{Co}-\mathrm{Mo}$ [13], on CNTs have also been carried out. Combining transition metals as hybrid catalysts for the synthesis of nanotubes is also believed to result in higher yield and better quality [14]. Moreover, particle aggregation due to the addition of metal catalysts could be prevented, thereby improving the shape, size, and morphology of particles, and thus, significantly affecting the growth of CNTs.

In previous studies, thin film catalysts have been formed on various substrates by either sputtering or electron-beam evaporation $[15,16]$. The catalyst film is then nucleated into particles by thermal annealing [17] or plasma treatment [18] to form the seed layer. Although the formation of catalyst particles is a key factor that determines the growth mechanism 
and nanotube diameter, only a few studies have explored the role of catalyst thickness in the growth process $[19,20]$, where strong correlation exists between the catalyst particle size and the growth of the nanotubes. The variation of nanotube structures can be formed during synthesis at different gas pressures [21]. Most researchers have concentrated on high gas pressure, typically from 1 Torr to 20 Torr, or atmospheric pressure to achieve high yield of CNTs [22, 23]. However, investigations on the viability of growing CNTs using hybrid metal catalysts at lower pressure are still lacking.

In this paper, a study on thermally grown MWCNTs using bimetallic cobalt-iron catalyst at low pressure is presented. The parameters affecting the growth of the nanotubes are investigated by varying the initial catalyst thickness and the gas pressure at low pressure. Results show that these parameters strongly influence nanotube diameter and growth rate. The results also provide a correlation between the formation of nanotube array and the measured sheet resistance.

\section{Experiment Details}

The synthesis of CNTs was performed by thermal CVD. Prior to the growth process, a thin film of bimetallic Co-Fe was deposited as catalyst onto a $10 \mathrm{~nm}$ TiN barrier layer/thermally oxidized $\mathrm{Si}$ (100) substrate through radio frequencymagnetron sputtering at a base pressure of $\sim 10^{-3} \mathrm{mbar}$. The Co-Fe composition varied at $20 \%$ and $50 \%$ with respect to $\% \mathrm{Co}$, whereas the catalyst thickness varied at 4, 6, 8, and $10 \mathrm{~nm}$. A short nucleation step involving plasma pretreatment of Co-Fe catalyst layer was performed for $10 \mathrm{~min}$ in the presence of hydrogen at $700^{\circ} \mathrm{C}$ with $200 \mathrm{~W}$ plasma power to break up the films into small particles and reduce the impurities. The nanotubes were then grown on the catalyst particles with an acetylene flow rate of $50 \mathrm{sccm}$ for $5 \mathrm{~min}$ by varying the gas pressure at $0.5,0.75$, and 1.0 Torr. Both the nucleated catalyst particles and the grown CNTs were characterized using a JEOL field emission scanning electron microscopy system. Raman spectra were obtained on the nanotube samples with a NT-MDT Raman spectroscopy system using a $473 \mathrm{~nm}$ air-cooled blue laser as an excitation for analysis. Emission intensities from the samples were measured from the peak height. For the electrical properties, the sheet resistance of the samples was measured at room temperature with an Ecopia-HMS5300 measurement system based on the van der Pauw method under a current excitation of $1 \mathrm{~mA}$.

\section{Results and Discussion}

3.1. Catalyst Particle Formation. Figure 1(a) illustrates the SEM images of the bimetallic Co-Fe catalyst distributed in the form of nanoparticles at $20 \%$ and $50 \%$ with respect to $\% \mathrm{Co}$ after plasma pretreatment at $700^{\circ} \mathrm{C}$. The $\mathrm{Co}-\mathrm{Fe}$ particles, which acted as a seeding layer prior to the growth of nanotubes, were formed during heating due to the surface tension and compressive stress between the TiN/Si (100) substrate and the Co-Fe catalyst as a result of the lattice mismatch in thermal expansion coefficients $[24,25]$. Based on the results, the size distribution of Co-Fe particles depends on the initial catalyst thickness of the sputtered $\mathrm{Co}-\mathrm{Fe}$, which in turn determines the particle formation. Figure 1(b) shows the dependence of average particle size and particle density on initial catalyst thickness. Catalyst formation at a $4 \mathrm{~nm}$ thick layer for both catalyst compositions was the densest, with small homogeneous particles due to small coalescence of the particles occurring during agglomeration. For a short nucleation time, a thinner catalyst was found to rapidly agglomerate, thereby forming small homogeneous particle sizes with minimal interparticle distance. Meanwhile, a largesized distribution with cluster-like particles possessing lower density was observed at the thicker Co-Fe catalyst. This occurrence is attributed to the nucleation and agglomeration of the particles that were incomplete in excess of the thick catalyst, resulting in broader size distribution.

In terms of Co composition in the Co-Fe catalyst, the $\mathrm{Co}_{50} \mathrm{Fe}_{50}$ catalyst exhibited higher particle density by more than $\sim 40 \%$ at the $4 \mathrm{~nm}$ thick catalyst due to the formation of smaller particle sizes compared with the $\mathrm{Co}_{20} \mathrm{Fe}_{80}$ catalyst. The particle density decreased with the increase in particle size because of the thicker catalyst. Therefore, a strong correlation possibly exists between the average particle size and the particle density with $4 \mathrm{~nm}$ to $10 \mathrm{~nm}$ thick Co-Fe catalysts.

3.2. Carbon Nanotube Growth. The influences of gas pressure during CNT growth are shown by the SEM images in Figure 2(a). No growth was observed at 0.5 Torr gas pressure on the $4 \mathrm{~nm}$ thick catalyst. However, highly dense "spaghettilike" CNT structures were observed when the pressure was increased to 1.0 Torr. The growth behavior as a function of gas pressure can be explained by the reaction between the catalyst activity and the dissolution, diffusion, and precipitation rates of the carbon atoms [21]. At 0.5 Torr, the dissolution and diffusion of carbon atoms into the seeding layers are limited because of the low concentration of carbon atoms. The high surface-to-volume ratio of small particles is very sensitive to passivation at high temperature without plasma with thinner Co-Fe catalyst layers [26]. This condition allows the amorphous carbon to react with the catalyst, thereby preventing the carbon feedstocks from diffusing into the particles [27]. Due to limited carbon feedstocks during a short growth time, nanotube growth is likely to be suppressed, subsequently resulting in the formation of a carbon shell around the CoFe particles. Meanwhile, the high concentration of carbon atoms at higher pressure of 1.0 Torr increases the diffusion and precipitation rates of carbon atoms, thus enabling their dissolution into the seed layers at higher rate, diffusion through the seed layers, and initiation of the growth process to form CNTs.

Figure 2(b) shows the Raman analysis for CNTs grown with $\mathrm{Co}_{20} \mathrm{Fe}_{80}$ and $\mathrm{Co}_{50} \mathrm{Fe}_{50}$ catalysts. Two major peaks are found, namely, a $G$-band at around $~ 1590 \mathrm{~cm}^{-1}$ and a $D$-band at around $\sim 1360 \mathrm{~cm}^{-1}$. The two-phonon $D$-band (2D) appears at $\sim 2690 \mathrm{~cm}^{-1}$. The results show that the present growth process only forms MWCNTs due to the absence of peaks at radial breathing mode frequency for single-walled carbon nanotubes. The $G$-band represents the ordered graphite corresponding to the stretching mode of the $\mathrm{C}-\mathrm{C}$ bonds in the 

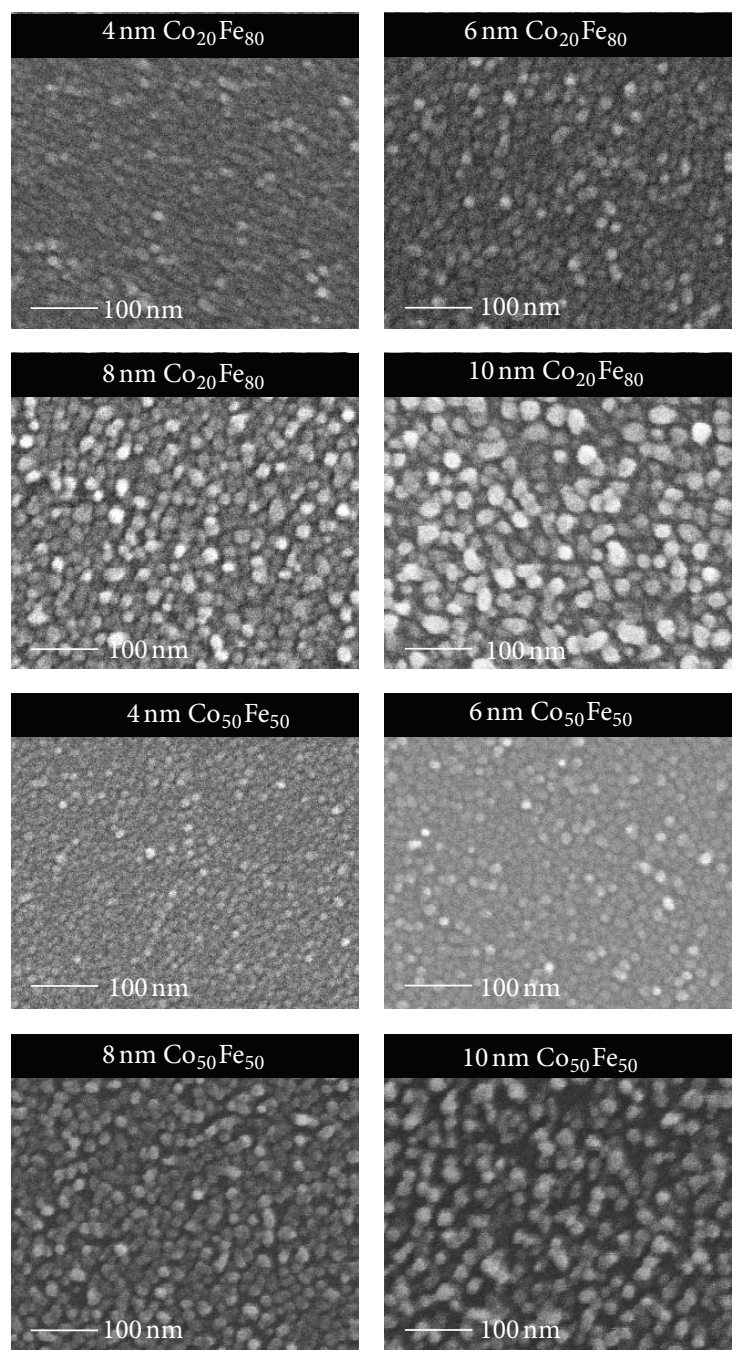

(a)

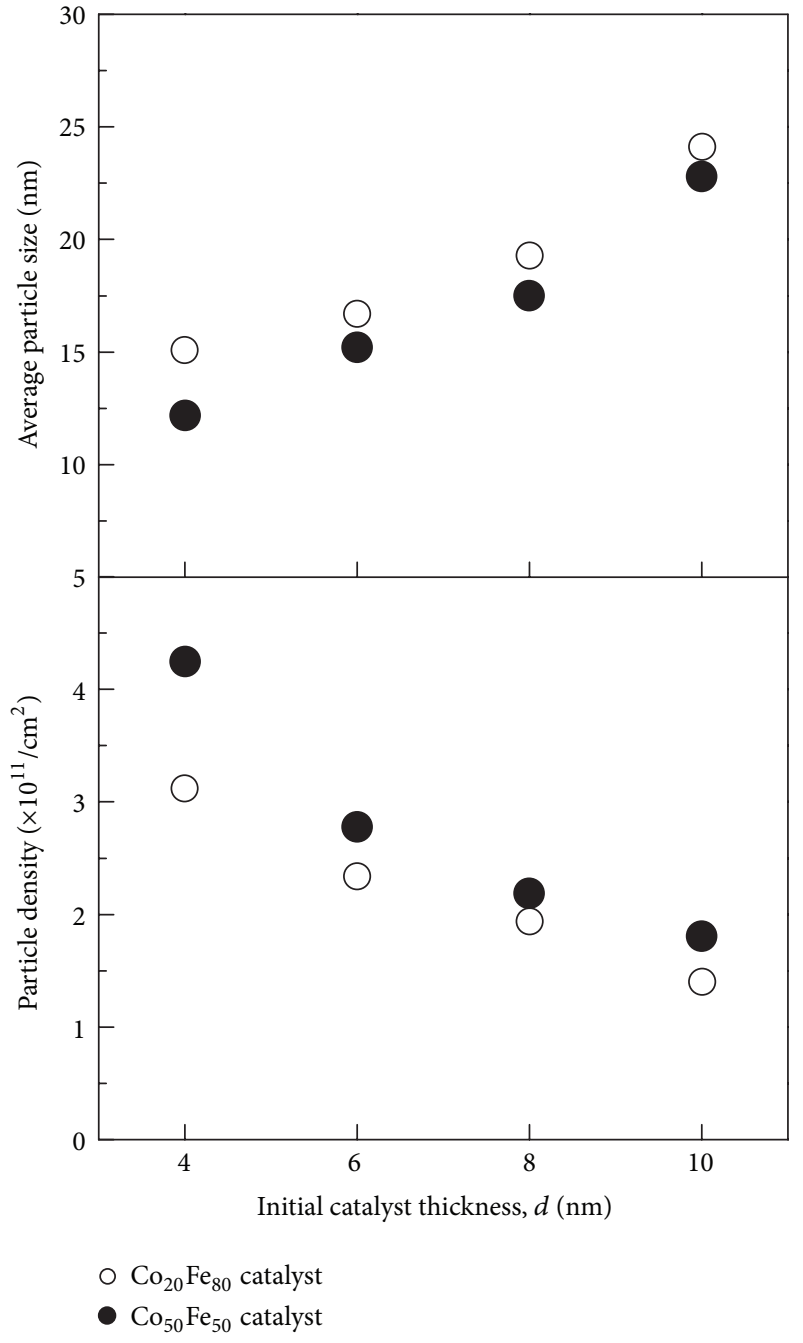

(b)

Figure 1: (a) SEM images of the formation of particles for $\mathrm{Co}_{20} \mathrm{Fe}_{80}$ and $\mathrm{Co}_{50} \mathrm{Fe}_{50}$ as a function of initial catalyst thickness after plasma pretreatment in $\mathrm{H}_{2}$ atmosphere for $10 \mathrm{~min}$. (b) Initial catalyst thickness dependence of average particle size and particle density.

graphite plane, whereas the $D$-band represents the disordered graphite associated with defects and amorphous carbon. The crystalline quality of the nanotubes can be evaluated based on the ratio of peak intensities $I_{G} / I_{D}$ (Figure 2(b)), except for the growth at a 0.5 Torr gas pressure, because no significant peak can be observed due to the lack of nanotube growth. The $I_{G} / I_{D}$ increased with increasing gas pressure from 0.75 Torr to 1.0 Torr, which in turn reduces the defects in the nanotubes. Meanwhile, an increase in $I_{G} / I_{D}$ up to $\sim 8 \%$ was also observed when the composition of Co in the catalyst was varied from $20 \%$ to $50 \%$. The amorphous carbons that may exist in thermally grown CNTs are not detectable through the SEM images. Alternatively, the observed increase in $I_{G} / I_{D}$ may be an indicator of the reduction in the amount of amorphous carbon. The Raman spectra analysis revealed that the CNTs deposited on the TiN barrier layer are of MWCNTs, resulting from a base growth due to strong $\mathrm{Co}-\mathrm{Fe}-\mathrm{TiN}$ interactions.

The correlation between the average particle size and the average nanotube diameter is shown in Figure 3(a). The results indicate that the nanotube diameter is dependent on the particle size, and the trend shows a nonlinear behavior. The increased particle size resulting from thicker catalyst increases the diameter of the nanotubes during the growth process. By varying the gas pressure from 0.5 Torr to 1.0 Torr, the diameter of the nanotubes tends to increase by more than $30 \%$ and $14 \%$ for the $\mathrm{Co}_{20} \mathrm{Fe}_{80}$ and $\mathrm{Co}_{50} \mathrm{Fe}_{50}$ catalysts, respectively. The nanotube diameter is less than the particle size, which presents a similar behavior as described in the previous studies of Kukovitsky et al. and Nasibulin et al. [28, 29]. Nanotube formation may be restricted during vertical growth on the $\mathrm{Co}-\mathrm{Fe}$ particles due to the strong interaction between the Co-Fe particles and the TiN layer. Therefore, the relationship between the particle size and the nanotube diameter becomes more complicated because gas pressure also influences nanotube diameter.

The growth rate curves which correspond to the catalyst composition and gas pressure as a function of initial catalyst thickness are demonstrated in Figure 3(b). The growth rate 

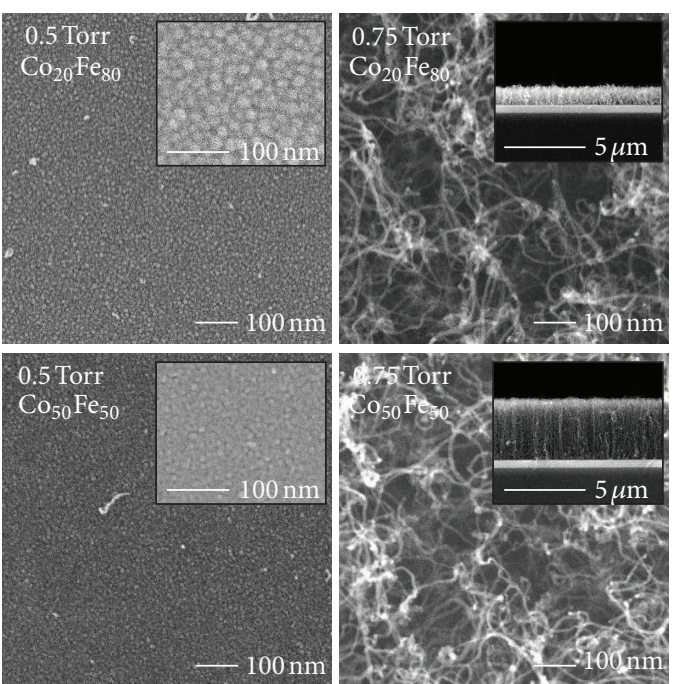

(a)

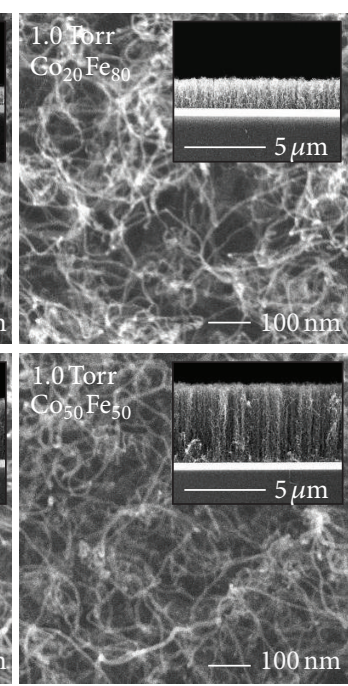

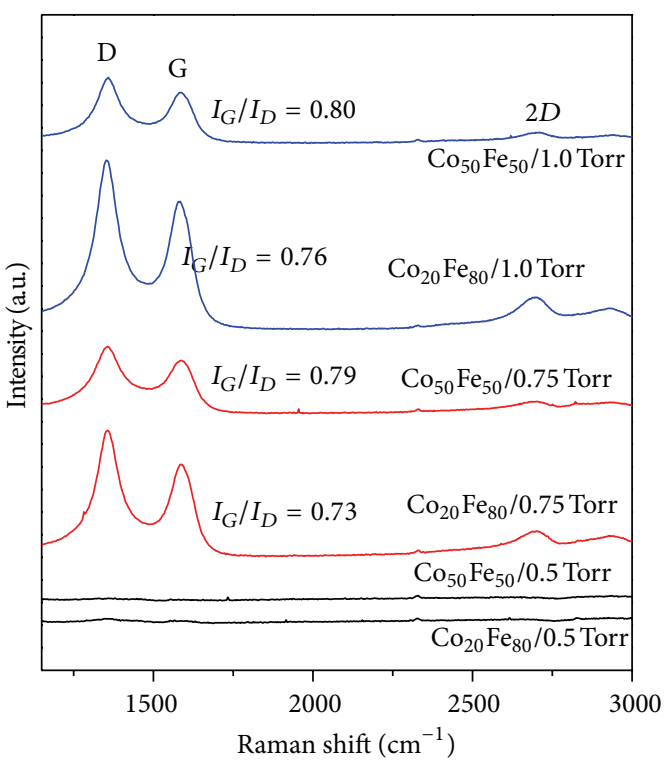

(b)

FIgURE 2: (a) SEM images of MWCNTs grown on $\mathrm{Co}_{20} \mathrm{Fe}_{80}$ and $\mathrm{Co}_{50} \mathrm{Fe}_{50}$ catalyst thickness of $4 \mathrm{~nm}$ at different pressures for 5 min. (b) Highfrequency Raman spectrum ( $473 \mathrm{~nm}$ excitation) of MWCNT at $4 \mathrm{~nm}$ thick catalyst. The relative ratio of the Raman bands $\left(I_{G} / I_{D}\right)$ reflects the quality of the presence of nanotubes.

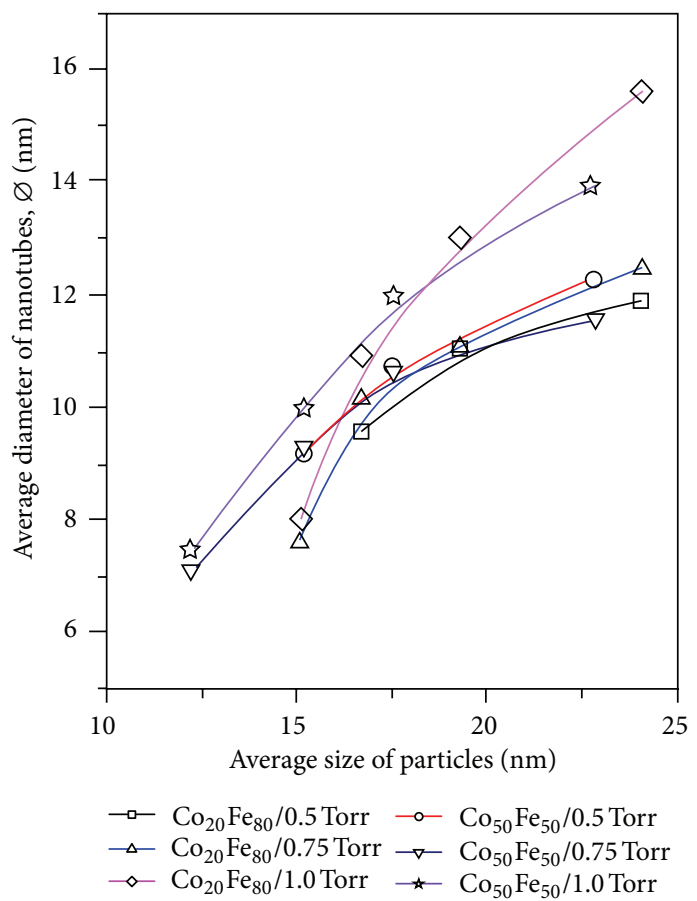

(a)

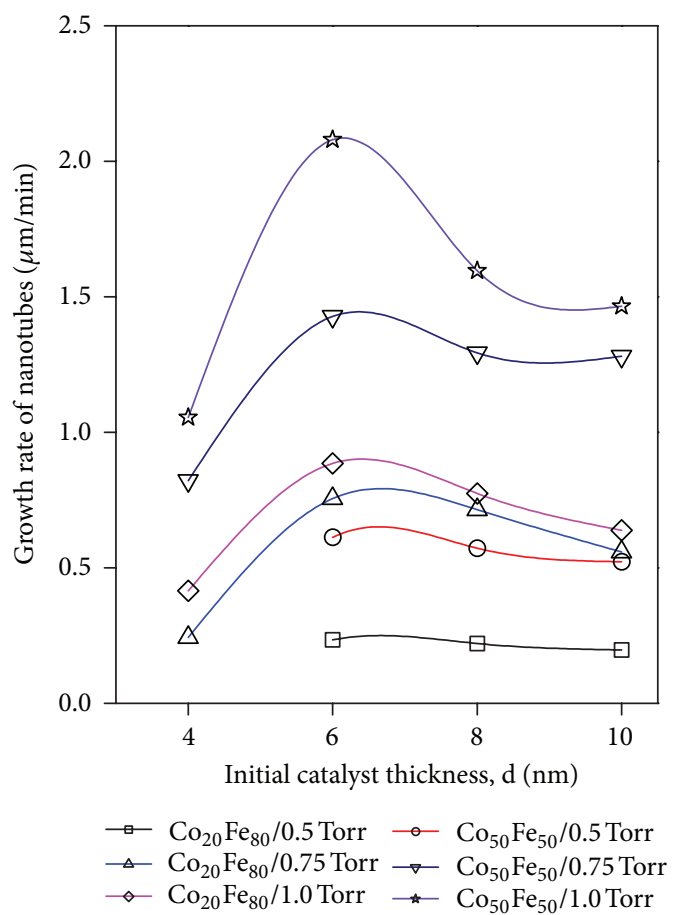

(b)

Figure 3: (a) Average diameter of the nanotubes as a function of average particle size. (b) Initial catalyst thickness dependence of the growth rate of nanotubes.

is obtained by measuring the height of the CNTs grown for $5 \mathrm{~min}$. The growth rate of CNTs grown using both $\mathrm{Co}_{20} \mathrm{Fe}_{80}$ and $\mathrm{Co}_{50} \mathrm{Fe}_{50}$ catalysts increased when the gas pressure increased from 0.5 Torr to 1.0 Torr due to higher precipitation rate of carbon atoms. The growth rate curve increased first with increased catalyst thickness and then decreased when the catalyst thickness was more than $6 \mathrm{~nm}$ as a result of the increased particle size. Larger particle sizes are expected to be 

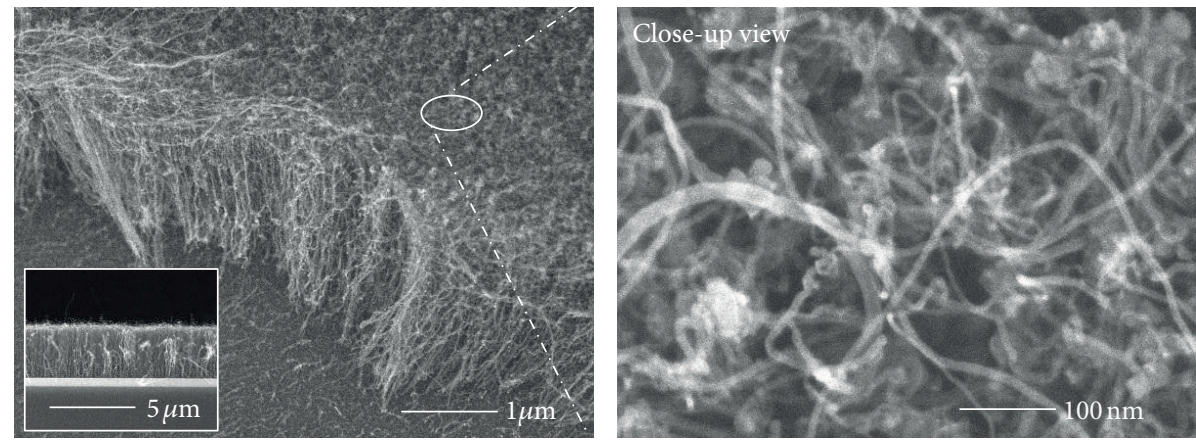

(a)
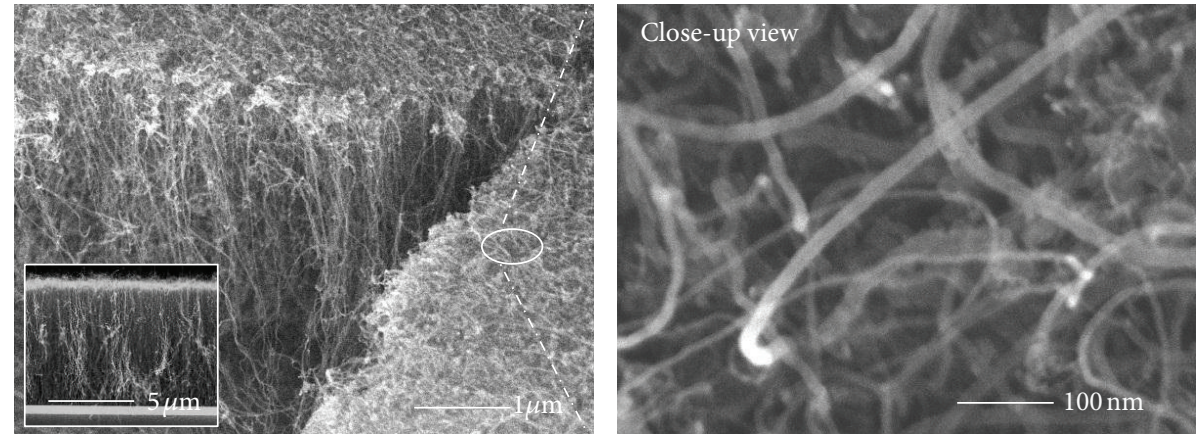

(b)

Figure 4: SEM images of MWCNTs grown on $10 \mathrm{~nm}$ thick catalysts of (a) $\mathrm{Co}_{20} \mathrm{Fe}_{80}$ and (b) $\mathrm{Co}_{50} \mathrm{Fe}_{50}$. The close-up views are taken from the top of the CNTs.

less energetic due to lower surface-to-volume ratio compared with smaller particle size. The diffusion and saturation of carbon atoms into the larger particles occurred at a lower rate, thereby forming short nanotubes at the end of the growth process. Based on the results, a significant growth rate of nanotubes was found on a $6 \mathrm{~nm}$ thick $\mathrm{Co}_{50} \mathrm{Fe}_{50}$ catalyst which was about $~ 1.4$ times higher compared with that of the $\mathrm{Co}_{20} \mathrm{Fe}_{80}$ catalyst. Clearly, higher Co composition in the catalyst has a role in improving the CNT growth rate, as shown in Figures 4(a) and 4(b). The result is also attributed to the formation of smaller $\mathrm{Co}_{50} \mathrm{Fe}_{50}$ catalyst particles compared with that of $\mathrm{Co}_{20} \mathrm{Fe}_{80}$ (as shown in Figure 1(a)), which has greater supersaturation rate of carbon feedstock to enhance CNTs growth.

Figure 5(a) shows the sheet resistance graph of MWCNTs against the initial catalyst thickness. For all cases, the sheet resistance initially decreased and then increased when the catalyst thickness is more than $6 \mathrm{~nm}$. The trend is opposite the results in Figure 3(b), so relating the contact resistance with the height of the nanotube is possible. Moreover, a much lower sheet resistance curve could also be seen on the nanotubes grown at higher gas pressure. For the 0.5 Torr gas pressure, the suppressed nanotubes grown on $4 \mathrm{~nm}$ thick catalysts of $\mathrm{Co}_{20} \mathrm{Fe}_{80}$ and $\mathrm{Co}_{50} \mathrm{Fe}_{50}$ in the form of carbon shells around the catalysts showed higher sheet resistance of about 17.4 and $13.8 \mathrm{k} \Omega$ /square, respectively. The lowest sheet resistance was observed in MWCNTs grown on $6 \mathrm{~nm}$ $\mathrm{Co}_{50} \mathrm{Fe}_{50}$ catalyst thickness at 1.0 Torr, where it decreased by about $98 \%$ relative to the highest sheet resistance. The formation of longer nanotubes grown on the $6 \mathrm{~nm}$ thick catalyst showed improved vertical alignment with higher density compared with those grown on the $4 \mathrm{~nm}$ thick catalyst, as shown in Figures 5(b) and 5(c). The presence of longer MWCNTs is expected to result in fewer end connections and larger contact area between the neighboring nanotubes due to the smallest gap among themselves, resulting in lower sheet resistance. This result suggests that electron transport in the nanotubes is limited by the tunneling effect between the gap and the adjacent nanotubes. The higher density of nanotubes resulting from longer nanotubes would increase the contact area among themselves. This condition improves electron hopping from one localized tube to another, thereby reducing resistance through the MWCNTs.

\section{Conclusions}

This paper presented an investigation on the effect of catalyst thickness and gas pressure on MWCNTs grown by CVD using bimetallic $\mathrm{Co}-\mathrm{Fe}$ layer. The $\mathrm{Co}-\mathrm{Fe}$ catalyst particle size (initial thickness) essentially influenced the nanotube diameter and the growth rate. The nanotube diameter was slightly lesser compared with the catalyst particle size. Thus, 1:1 ratio between the catalyst particle size and the nanotube diameter did not exist. Results also showed that nanotubes grew at a rapid rate when a $6 \mathrm{~nm}$ thick catalyst was used, and the rate appeared to be slower when the catalyst thickness 


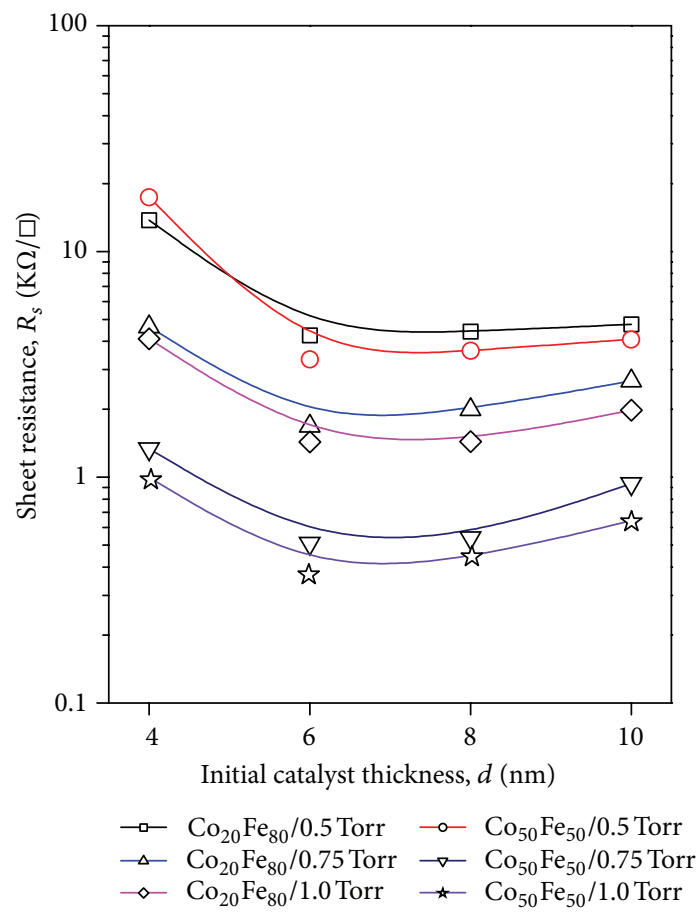

(a)

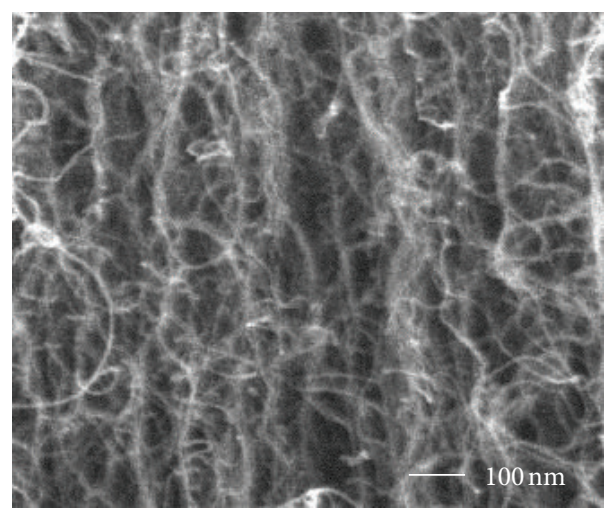

(b)

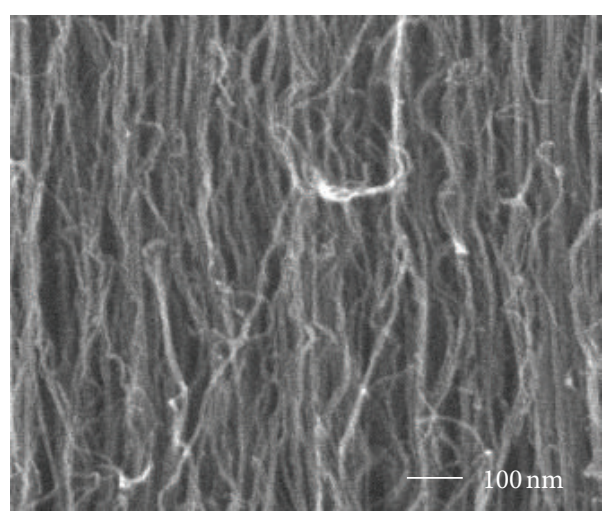

(c)

FIGURE 5: (a) A plot of sheet resistance versus initial catalyst thickness of $\mathrm{Co}_{20} \mathrm{Fe}_{80}$ and $\mathrm{Co}_{50} \mathrm{Fe}_{50}$. The measurements were taken at room temperature. (b) Low density of MWCNTs grown on $4 \mathrm{~nm} \mathrm{Co}_{50} \mathrm{Fe}_{50}$ catalyst thickness and (c) high density of MWCNTs grown on $6 \mathrm{~nm}$ $\mathrm{Co}_{50} \mathrm{Fe}_{50}$ catalyst thickness at 1.0 Torr gas pressure.

was further increased to $10 \mathrm{~nm}$. However, the growth rate of the nanotubes could be improved by increasing gas pressure during the growth process due to the higher concentration of the carbon feedstock. A significant growth rate of nanotubes appeared at $6 \mathrm{~nm} \mathrm{Co}{ }_{50} \mathrm{Fe}_{50}$ catalyst thickness, which was $\sim 1.4$ times higher compared with that of the $\mathrm{Co}_{20} \mathrm{Fe}_{80}$ catalyst due to the formation of smaller-sized particles. As a result, an improved electrical sheet resistance could be observed from the longer MWCNTs grown on the $\mathrm{Co}_{50} \mathrm{Fe}_{50}$ catalyst. The higher density of the MWCNTs from longer nanotube formation improved the contact area between the neighboring nanotubes, resulting in lower sheet resistance. Moreover, the Raman spectra results also showed that the quality of the CNTs grown on $\mathrm{Co}_{50} \mathrm{Fe}_{50}$ catalyst was better by about $\sim 8 \%$ compared with that of the $\mathrm{Co}_{20} \mathrm{Fe}_{80}$ catalyst.

\section{Acknowledgments}

This research was supported by the National Nanotechnology Directorate Funding NND/ND/(2)/TD11-012 and the eScience Funding 01-03-04-SF0027 under the Ministry of Science, Technology, and Innovation (MOSTI), Malaysia, and ERGS 203/PMEKANIK/6730069 under the Ministry of Higher Education (MOHE), Malaysia.

\section{References}

[1] H. Li, J. Li, and C. Gu, "Local field emission from individual vertical carbon nanofibers grown on tungsten filament," Carbon, vol. 43, no. 4, pp. 849-853, 2005. 
[2] E. Yenilmez, Q. Wang, R. J. Chen, D. Wang, and H. Dai, "Wafer scale production of carbon nanotube scanning probe tips for atomic force microscopy," Applied Physics Letters, vol. 80, no. 12, pp. 2225-2227, 2002.

[3] D. R. Kauffman and A. Star, "Carbon nanotube gas and vapor sensors," Angewandte Chemie, vol. 47, no. 35, pp. 6550-6570, 2008.

[4] B. Kim, H. Chung, and W. Kim, "High-performance supercapacitors based on vertically aligned carbon nanotubes and nonaqueous electrolytes," Nanotechnology, vol. 23, no. 15, Article ID 155401, 2012.

[5] W. B. Choi, J. U. Chu, K. S. Jeong et al., "Ultrahigh-density nanotransistors by using selectively grown vertical carbon nanotubes," Applied Physics Letters, vol. 79, no. 22, pp. 36963698, 2001.

[6] C. Klinke, J.-M. Bonard, and K. Kern, "Comparative study of the catalytic growth of patterned carbon nanotube films," Surface Science, vol. 492, no. 1-2, pp. 195-201, 2001.

[7] A. J. Hart, B. O. Boskovic, A. T. H. Chuang et al., "Uniform and selective CVD growth of carbon nanotubes and nanofibres on arbitrarily microstructured silicon surfaces," Nanotechnology, vol. 17, no. 5, pp. 1397-1403, 2006.

[8] Y. Wang, Z. Luo, B. Li et al., "Comparison study of catalyst nanoparticle formation and carbon nanotube growth: support effect," Journal of Applied Physics, vol. 101, no. 12, Article ID 124310, 2007.

[9] S. Esconjauregui, B. C. Bayer, M. Fouquet et al., "Use of plasma treatment to grow carbon nanotube forests on TiN substrate," Journal of Applied Physics, vol. 109, no. 11, Article ID 114312, 2011.

[10] A. K. M. F. Kibria, Y. H. Mo, M. H. Yun, M. J. Kim, and K. S. Nahm, "Effects of bimetallic catalyst composition and growth parameters on the growth density and diameter of carbon nanotubes," Korean Journal of Chemical Engineering, vol. 18, no. 2, pp. 208-214, 2001.

[11] L. G. Bulusheva, A. V. Okotrub, A. G. Kudashov et al., "Effect of $\mathrm{Fe} / \mathrm{Ni}$ catalyst composition on nitrogen doping and field emission properties of carbon nanotubes," Carbon, vol. 46, no. 6, pp. 864-869, 2008.

[12] Y. Li, J. Liu, Y. Wang, and Z. L. W. Zhong Lin Wang, "Preparation of monodispersed Fe-Mo nanoparticles as the catalyst for CVD synthesis of carbon nanotubes," Chemistry of Materials, vol. 13, no. 3, pp. 1008-1014, 2001.

[13] X. Z. Liao, A. Serquis, Q. X. Jia, D. E. Peterson, Y. T. Zhu, and H. F. Xu, "Effect of catalyst composition on carbon nanotube growth," Applied Physics Letters, vol. 82, no. 16, pp. 2694-2696, 2003.

[14] Z. Kónya, J. Kiss, A. Oszkó, A. Siska, and I. Kiricsi, "XPS characterisation of catalysts during production of multiwalled carbon nanotubes," Physical Chemistry Chemical Physics, vol. 3, no. 1, pp. 155-158, 2001.

[15] Y. M. Shin, S. Y. Jeong, H. J. Jeong et al., "Influence of morphology of catalyst thin film on vertically aligned carbon nanotube growth," Journal of Crystal Growth, vol. 271, no. 1-2, pp. 81-89, 2004.

[16] Z. L. Gao, K. Zhang, and M. M. F. Yuen, "Fabrication of carbon nanotube thermal interface material on aluminum alloy substrates with low pressure CVD," Nanotechnology, vol. 22, no. 26, Article ID 265611, 2011.

[17] S. A. Moshkalyov, A. L. D. Moreau, H. R. Guttiérrez, M. A. Cotta, and J. W. Swart, "Carbon nanotubes growth by chemical vapor deposition using thin film nickel catalyst," Materials Science and Engineering B, vol. 112, no. 2-3, pp. 147-153, 2004.
[18] H. S. Uh, S. S. Park, and B. W. Kim, "Effect of catalyst thickness and plasma pretreatment on the growth of carbon nanotubes and their field emission properties," Journal of Nanoscience and Nanotechnology, vol. 7, no. 11, pp. 3731-3735, 2007.

[19] M. Chhowalla, K. B. K. Teo, C. Ducati et al., "Growth process conditions of vertically aligned carbon nanotubes using plasma enhanced chemical vapor deposition," Journal of Applied Physics, vol. 90, no. 10, pp. 5308-5317, 2001.

[20] S. Hofmann, M. Cantoro, B. Kleinsorge et al., "Effects of catalyst film thickness on plasma-enhanced carbon nanotube growth," Journal of Applied Physics, vol. 98, Article ID 034308, 2005.

[21] W. Z. Li, J. G. Wen, Y. Tu, and Z. F. Ren, "Effect of gas pressure on the growth and structure of carbon nanotubes by chemical vapor deposition," Applied Physics A, vol. 73, no. 2, pp. 259-264, 2001.

[22] M. Meyyappan, L. Delzeit, A. Cassell, and D. Hash, "Carbon nanotube growth by PECVD: a review," Plasma Sources Science and Technology, vol. 12, no. 2, pp. 205-216, 2003.

[23] M. Kumar and Y. Ando, "Controlling the diameter distribution of carbon nanotubes grown from camphor on a zeolite support," Carbon, vol. 43, no. 3, pp. 533-540, 2005.

[24] C. Bower, O. Zhou, W. Zhu, D. J. Werder, and S. Jin, "Nucleation and growth of carbon nanotubes by microwave plasma chemical vapor deposition," Applied Physics Letters, vol. 77, no. 17, pp. 2767-2769, 2000.

[25] V. I. Merkulov, D. H. Lowndes, Y. Y. Wei, G. Eres, and E. Voelkl, "Patterned growth of individual and multiple vertically aligned carbon nanofibers," Applied Physics Letters, vol. 76, no. 24, pp. 3555-3557, 2000.

[26] R. Löffler, M. Häffner, G. Visanescu et al., "Optimization of plasma-enhanced chemical vapor deposition parameters for the growth of individual vertical carbon nanotubes as field emitters," Carbon, vol. 49, no. 13, pp. 4197-4203, 2011.

[27] B. K. Teo, C. Singh, M. Chhowalla, and W. I. Milne, "Catalytic synthesis of carbon nanotubes and nanofibers," Encyclopedia of Nanoscience and Nanotechnology, vol. 10, pp. 1-22, 2003.

[28] E. F. Kukovitsky, S. G. L'vov, N. A. Sainov, V. A. Shustov, and L. A. Chernozatonskii, "Correlation between metal catalyst particle size and carbon nanotube growth," Chemical Physics Letters, vol. 355, no. 5-6, pp. 497-503, 2002.

[29] A. G. Nasibulin, P. V. Pikhitsa, H. Jiang, and E. I. Kauppinen, "Correlation between catalyst particle and single-walled carbon nanotube diameters," Carbon, vol. 43, no. 11, pp. 2251-2257, 2005. 

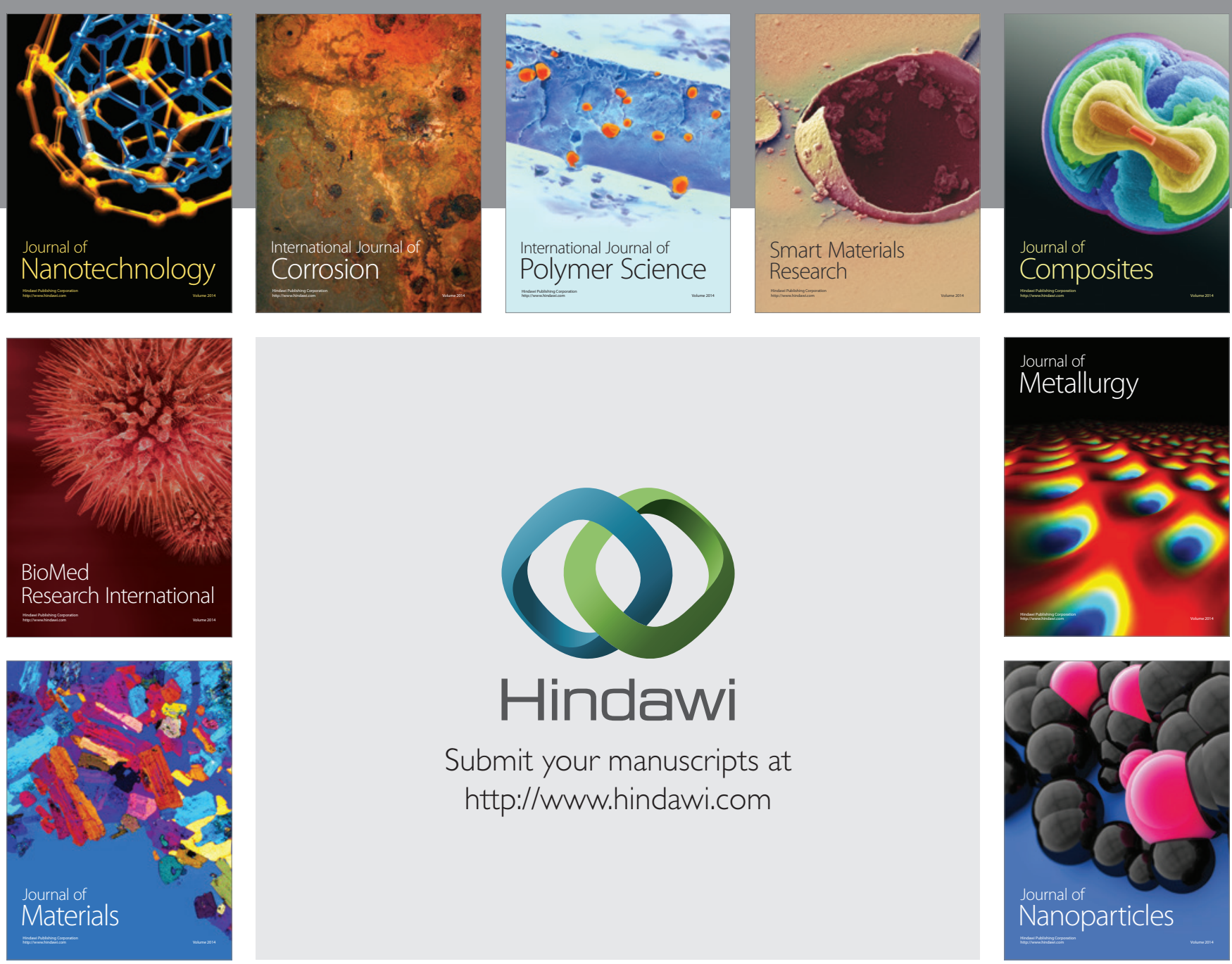

Submit your manuscripts at http://www.hindawi.com
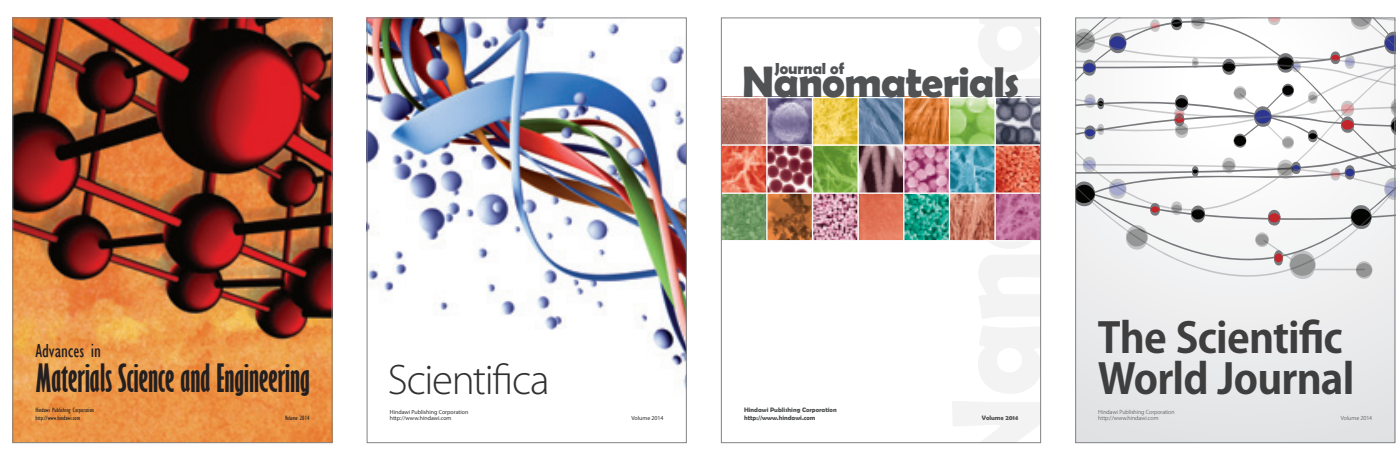

\section{The Scientific World Journal}
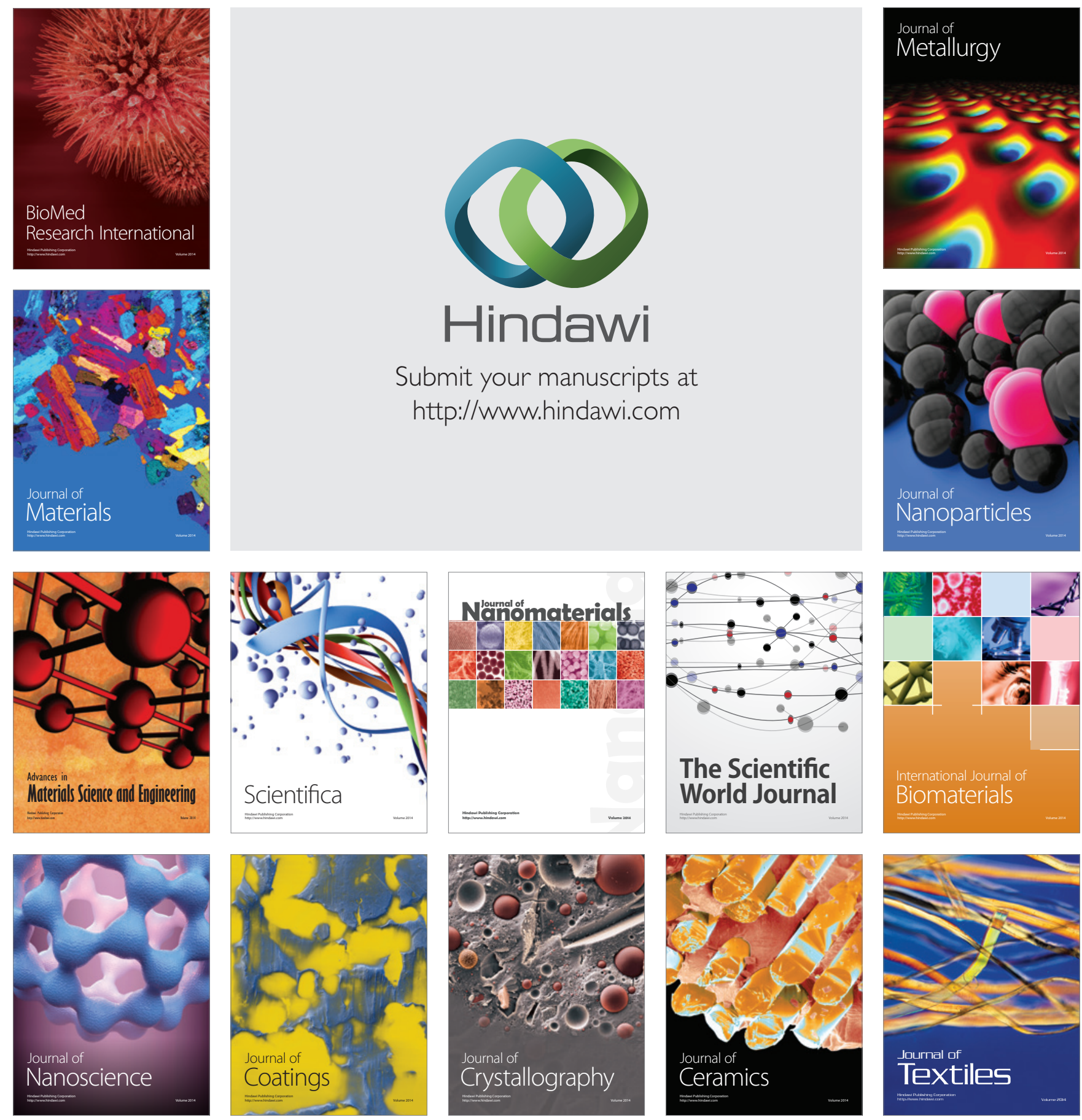